\title{
Revestimento ativo de amido na conservação pós-colheita de pera Williams minimamente processada
}

\author{
Starch-based edible coating on extending shelf life of fresh-cut pear
}

\author{
Diego Alvarenga Botrel ${ }^{*}$ Nilda de Fátima Ferreira Soares ${ }^{\mathrm{II}}$ Geany Peruch Camilloto ${ }^{\mathrm{II}}$ \\ Regiane Victória de Barros Fernandes ${ }^{\mathrm{I}}$
}

\section{RESUMO}

A pera é uma das frutas de clima temperado mais consumidas no Brasil, no entanto sua conservação é limitada devido ao seu escurecimento quando sofre danos ou tratamentos físicos. Os revestimentos comestíveis interagem favoravelmente com o alimento, aumentando sua vida de prateleira. Este trabalho objetivou avaliar a ação de revestimento de amido adicionado de lactato de cálcio e Lcisteína na inibição do escurecimento enzimático, na redução do crescimento de psicrotrófilos e enterobactérias e na manutenção da textura. As peras fatiadas foram cobertas com revestimentos comestíveis à base de amido incorporados com cisteína e lactato de cálcio, exceto o controle - sem revestimento $(C)$. Os tratamentos foram: apenas revestimento (T1); 2,0\% lactato de cálcio e 1,0\% L-cisteína (T2) e 2,0\% lactato de cálcio e 1,5\% L-cisteína (T3). As amostragens foram feitas nos tempos zero, dois, quatro e seis dias. As amostras foram mantidas sob refrigeração $\left(7^{\circ} \mathrm{C} \pm 2^{\circ} \mathrm{C}\right)$. As peras submetidas aos tratamentos T2 e T3 apresentaram-se significativamente mais firmes $(P<0,05)$ que as dos tratamentos $C$ e T1. A ação da cisteína sobre a inibição do escurecimento enzimático foi observada nos tratamentos T2 e T3, que não apresentaram diferença significativa $(P \geq 0,05)$ entre si para os valores de $\Delta E$, no entanto esses valores foram significativamente menores em relação ao controle. No tempo 6, a redução decimal na contagem de psicrotrófilos chegou a 3,03 e 2,43 para T3 e T2, em comparação com o controle. A contagem de enterobactérias apresentou comportamento semelhante, sendo o valor da redução de 3,16 e 3,05 para T2 e T3 em relação ao controle. Verificou-se que a vida de prateleira de pera minimamente processada pode ser mantida por mais tempo com o uso desse revestimento.

Palavras-chave: processamento mínimo, Pyrus communis, qualidade, revestimento comestível.

\begin{abstract}
Pear is one of the most consumed temperate fruits in Brazil; however their conservation is limited due to browning when it suffers injuries or physical treatments. The edibles coating interact with the food positively extending its shelf life. This research aimed to evaluate the action of starch edible coating incorporated with calcium lactate and L-cysteine on enzymatic browning inhibition, on psychrotrophs and enterobacteriaceae growing reduction and on firmness maintenance. The sliced pears were coated with starch edible coating incorporated with L-cysteine and calcium lactate, except control, without coating $(C)$. The treatment were: only coating (T1); 2,0\% calcium lactate and 1,0\% L-cysteine (T2); 2,0\% calcium lactate and 1,5\% L-cysteine (T3). The samples were taken at 0, 2, 4 and 6 days. Pears were keeped under refrigeration $\left(7^{\circ} \mathrm{C} \pm 2^{\circ} \mathrm{C}\right)$. Pears submitted to treatments $T 2$ and $T 3$ show significantly more firms $(P<0,05)$ compared to treatments $C$ and T1. Cysteine action over enzymatic browning inhibition was observed in treatments $T 2$ and T3 which do not differed significantly each other $(P \geq 0,05)$ to $\triangle E$ values however these were significantly lower than control $(C)$. At time 6, decimal reduction on psychrotrophs counting reached 3,03 and 2,43 to T3 e T2 compared to control. Enterobacteriaceae counting showed similar behavior where the reduction values were 3,16 and 3,05 to T2 e T3 compared to control. It was verified that using the studied edible coating on fresh cut pear can extend its shelf life.
\end{abstract}

Key words: minimally processing, Pyrus communis, quality, edible coating.

\section{INTRODUÇÃO}

A pera (Pyrus communis) é atualmente a terceira fruta de clima temperado mais consumida no

'Universidade Federal de Viçosa (UFV), Campus de Rio Paranaíba, 38810-000, Rio Paranaíba, MG, Brasil. E-mail: diego.botrel@ufv.br. ${ }^{*}$ Autor para correspondência.

IIDepartamento de Tecnologia de Alimentos, UFV, Viçosa, MG, Brasil. 
Brasil, após a maçã e o pêssego. Porém, a produção da pereira representa, no Brasil, uma potencialidade ainda não explorada a contento pela fruticultura brasileira, com o abastecimento sendo realizado principalmente com aquisições de outros países. Assim, seu cultivo pode ser uma alternativa de produção importante aos agricultores brasileiros, em especial das regiões de clima subtropical. As características que compõem o conceito de qualidade de um produto alimentício estão ligadas às características sensoriais, nutricionais e microbiológicas, as quais durante o período referente à estocagem e comercialização, podem ser alteradas. Diversos processos químicos e físicos têm sido estudados com o intuito de serem aplicados para preservar a qualidade dos alimentos, sendo necessária uma embalagem adequada para a conservação e comercialização do produto (DEBEAUFORT et al., 1998). Os filmes e revestimentos comestíveis têm demonstrado ser uma técnica eficaz de preservação de frutas e hortaliças para manter boa aparência e firmeza, mantendo, assim, o valor comercial (XU et al., 2002). Revestimentos comestíveis podem ser usados para inibir a migração da umidade, oxigênio, dióxido de carbono, aromas e lipídeos, e introduzir aditivos como antioxidantes e antimicrobianos, melhorando assim as características intrínsecas e a integridade mecânica dos vegetais recobertos. Pesquisas recentes têm explorado o potencial dos revestimentos comestíveis para manter e estender a qualidade e a vida útil de produtos frescos, tais como maçã (ROJAS-GRAU et al., 2007), manga (CHIEN et al., 2007) e melão (RAYBAUDI-MASSILIA et al., 2008). A condição físico-química dos produtos minimamente processados torna-se meio propício para o crescimento de microrganismos, devido à lesão dos tecidos e ao seu alto teor de umidade, o que aumenta o potencial de deterioração. Por serem manipulados em diversas etapas até a obtenção do produto pronto e fresco para o consumo, esses produtos podem ter sua microbiota aumentada, alterada e, eventualmente, veicular microrganismos patogênicos. Entre os microrganismos encontrados nesses produtos, podem ser destacados as leveduras, os fungos, os mesófilos e os psicrotróficos (RAYBAUDI-MASSILIA et al., 2008), incluindo também coliformes (PAULA, et al., 2009). O objetivo deste trabalho foi avaliar a ação de revestimento de amido adicionado de L-cisteína e lactato de cálcio na conservação de peras (Pyrus communis) minimamente processadas durante o armazenamento refrigerado.

\section{MATERIAL E MÉTODOS}

Processamento

Peras Williams (Pyrus communis) foram adquiridas no comércio local, no estádio de maturação comercial. Os frutos foram selecionados, sanitizados em solução de Sumaveg $® 200 p p m$ de cloro residual e, posteriormente, lavados com $3 \mathrm{ppm}$ de cloro residual também em solução de Sumaveg $®$ durante 15 minutos cada. Foram descascados, e as fatias foram cortadas no formato de meia-lua, com auxílio de facas de aço inoxidável. A temperatura do ambiente de processamento, na Unidade de Processamento Mínimo, se manteve em $15^{\circ} \mathrm{C} \pm 2^{\circ} \mathrm{C}$. As fatias de pera foram submetidas aos tratamentos, todos revestidos com filme comestível, exceto o controle - sem revestimento $(\mathrm{C})$. Os outros tratamentos foram divididos em: apenas revestimento (T1); revestimento com $2 \%$ lactato de cálcio e 1,0\% L-cisteína (T2); e revestimento $2 \%$ lactato de cálcio e 1,5\% L-cisteína (T3). As peras fatiadas submetidas aos tratamentos T1, T2 e T3 foram imersas em soluções de revestimento por três minutos e levadas à secagem com auxílio de ventilador, em ambiente refrigerado $\left(15^{\circ} \mathrm{C}\right)$, por 120 minutos. O material foi acondicionado em potes de Polietileno Tereftalato (PET) com $10 \mathrm{~cm}$ de diâmetro e $10 \mathrm{~cm}$ de altura, contendo cerca de $100 \mathrm{~g}$ de produto. Concluído o procedimento, as peras minimamente processadas foram mantidas sob refrigeração $\left(7^{\circ} \mathrm{C} \pm 2^{\circ} \mathrm{C}\right)$ por um período de seis dias. As amostragens foram feitas no tempo zero ( $5 \mathrm{~h}$ após o processamento) e de dois em dois dias. As amostras foram avaliadas quanto à textura, cor, composição química e contagem microbiológica.

\section{Análises físico-químicas}

O teor de sólidos solúveis da polpa da pera foi determinado por refratometria. Os valores de acidez titulável foram determinados por titulação com $\mathrm{NaOH} 0,1 \mathrm{~N}$ e expressos em porcentagem de ácido málico. A leitura dos valores de $\mathrm{pH}$ foi realizada com auxílio de potenciômetro (Digimed DM20). Todas as análises citadas foram realizadas de acordo com as normas analíticas do Instituto Adolfo Lutz (BRASIL, 2005). A perda de massa fresca foi determinada com a pesagem das caixas contendo as peras, sendo utilizada balança semi-analítica (Gehaka BG 400), a cada 24 horas, durante os seis dias de estocagem. Os resultados foram expressos em porcentagem de perda de massa, considerandose a diferença entre o peso inicial do fruto e aquele obtido em cada período de amostragem. A textura das fatias de pera foi avaliada utilizado o Aparelho 
Universal de Testes Instron (Modelo 3366), segundo metodologia adaptada e descrita por LUNA GUZMÁN \& BARRETT (2000). As fatias de pera apresentaram $1 \mathrm{~cm}$ de espessura. $\mathrm{O}$ aparelho foi operado em uma velocidade de $1 \mathrm{~mm} \mathrm{~s}^{-1}$, sendo utilizadas uma carga de $1 \mathrm{kN}$ e uma sonda para perfuração de $5 \mathrm{~mm}$ de diâmetro, cilíndrica e de ponta plana. Os valores de carga máxima suportada pelas fatias foram expressos em Newtons (N). As alterações na coloração superficial do produto foram acompanhadas com um colorímetro (Color Reader CR-10 Minolta). Os parâmetros a* (cromaticidade no eixo da cor verde para vermelha), b* (cromaticidade no eixo da cor azul para amarelo) e L* (luminosidade) foram utilizados para o cálculo do $\Delta \mathrm{E}$ (diferença de cor), de acordo com a equação (1):

$\Delta E=\sqrt{\left[(\Delta L *)^{2}+(\Delta a *)^{2}+(\Delta b *)^{2}\right]}$

em que $\Delta \mathrm{L}, \Delta \mathrm{a}$ e $\Delta \mathrm{b}$ representam a diferença entre os parâmetros de cor da amostra no tempo estudado e no tempo zero, de acordo com metodologia descrita por GENNADIOS et al. (1996).

Análises microbiológicas

Amostras de peras minimamente processadas foram avaliadas quanto à presença de psicrotrófilos e enterobactérias, segundo metodologia descrita por VANDERZANT \& SPLITTOESSER (1992). A contagem de microrganismos psicrotrófilos foi realizada durante os seis dias do período de estocagem, e a contagem de enterobactérias ocorreu apenas no último dia de estocagem, a $7^{\circ} \mathrm{C} \pm 2^{\circ} \mathrm{C}$.

Análises dos resultados

$\mathrm{O}$ experimento foi conduzido com três repetições, em delineamento inteiramente casualizado. Aplicou-se teste Tukey para avaliar a diferença entre as médias dos tratamentos. As análises foram realizadas com auxílio do programa Statistical Analysis System (SAS), versão 9.1.

\section{RESULTADOS E DISCUSSÃO}

Análises físico-químicas

Todas as variáveis físico-químicas estudadas não foram afetadas significativamente $(\mathrm{P}=0,05)$ pela interação entre tratamento e tempo de armazenamento. As variáveis ${ }^{\circ}$ Brix, acidez titulável e $\mathrm{pH}$ não variaram significativamente $(\mathrm{P}=0,05)$ com o tempo de estocagem (Tabela 1).

O valor de sólidos solúveis encontrado foi de, em média, $13,7^{\circ} \mathrm{Brix}$, sendo similar ao citado por outros pesquisadores, tais como SILVA et al. (2002), que encontraram valores variando entre $(11,7$ e 15,1) ${ }^{\circ}$ Brix em pera (Pyrus communis L.).

As peras submetidas aos tratamentos $\mathrm{T} 2 \mathrm{e}$ T3 obtiveram os maiores valores de acidez titulável e, consequentemente, menores valores para $\mathrm{pH}$. Os revestimentos contendo lactato de cálcio permitiram manutenção dos valores de acidez mais altos, provavelmente devido à atuação do cálcio sobre a respiração dos frutos. Segundo PINHEIRO et al. (2005), a diminuição da acidez e o aumento do $\mathrm{pH}$ são característicos da fase de senescência dos frutos e decorrentes do metabolismo de ácidos orgânicos. O cálcio contribui para controlar desordens fisiológicas e retardar o processo de senescência, visto que proporciona uma maior resistência na parede celular, dificultando a ação de enzimas pécticas, com consequente aumento da vida útil.

REIS et al. (2004), avaliando o efeito da atmosfera modificada ativamente com as concentrações iniciais de $2 \% \mathrm{O}_{2}+10 \% \mathrm{CO}_{2}$ e dos tratamentos químicos (L-cisteína, ácido ascórbico, cloreto de cálcio) sobre a vida de prateleira e qualidade de banana-prata minimamente processada, observaram que as amostras dos tratamentos químicos apresentaram, estatisticamente, os menores valores de

Tabela 1 - Valores médios de ${ }^{\circ}$ Brix, acidez titulável e $\mathrm{pH}$ das peras minimamente processadas, durante seis dias de estocagem, a $7^{\circ} \mathrm{C} \pm 2^{\circ} \mathrm{C}$, e submetidas aos diferentes tratamentos: Controle (C), apenas revestimento (T1); revestimento com 2,0\% lactato de cálcio e $1,0 \%$ Lcisteína (T2); revestimento com 2,0\% lactato de cálcio e 1,5\% L-cisteína (T3).

\begin{tabular}{lccc}
\hline Tratamentos & Sólidos solúveis ( ${ }^{\circ}$ Brix $)$ & Acidez titulável & \\
& & $\left(\mathrm{g}\right.$ ac. Málico.100g pera $\left.{ }^{-1}\right)$ & $\mathrm{pH}$ \\
\hline $\mathrm{C}$ & $13,6 \pm 1,11 \mathrm{a}$ & $0,77 \pm 0,32 \mathrm{a}$ & $4,06 \pm 0,09 \mathrm{a}$ \\
$\mathrm{T} 1$ & $13,2 \pm 1,23 \mathrm{a}$ & $0,74 \pm 0,09 \mathrm{a}$ & $3,03 \pm 0,11 \mathrm{a}$ \\
$\mathrm{T} 2$ & $13,9 \pm 1,45 \mathrm{a}$ & $0,81 \pm 0,09 \mathrm{ab}$ & $3,98 \pm 0,07 \mathrm{ab}$ \\
T3 & $14,1 \pm 0,99 \mathrm{a}$ & $0,88 \pm 0,08 \mathrm{~b}$ & $3,04 \mathrm{~b}$ \\
\hline
\end{tabular}

Médias seguidas da mesma letra não diferem entre si pelo teste de Tukey ( $\mathrm{P} \geq 0,05)$.

Ciência Rural, v.40, n.8, ago, 2010. 
pH, em comparação com os grupos controle e em atmosfera modificada ativa.

Os valores de perda de peso ao longo do tempo apresentaram diferença significativa $(\mathrm{P}<0,05)$ entre os tratamentos e ao longo do tempo. Apesar dessa diferença, observou-se uma baixa perda de massa, atingindo o valor máximo de $0,08 \%$. REIS et al. (2004) também observaram baixa perda de massa, em torno de $0,13 \%$, em banana-prata minimamente processada e submetida à atmosfera modificada ativamente com as concentrações iniciais de $2 \%$ $\mathrm{O}_{2}+10 \% \mathrm{CO}_{2}$ e com os tratamentos químicos (Lcisteína, ácido ascórbico, cloreto de cálcio).

Os tratamentos $\mathrm{T} 2$ e $\mathrm{T} 3$, adicionados de lactato de cálcio, apresentaram maior firmeza e se mostraram significativamente diferentes $(\mathrm{P}<0,05) \mathrm{em}$ relação aos tratamentos C e T1 (Figura 1). Segundo PINHEIRO et al. (2005), o aumento dos níveis de cálcio no fruto proporciona uma maior resistência na parede celular, dificultando a ação de enzimas pécticas e promovendo uma maior integridade às células, com consequente controle de desordens fisiológicas e aumento da vida útil dos frutos. O cálcio estabiliza membranas e paredes celulares, preservando sua integridade e funcionalidade e protegendo-as da clivagem por enzimas hidrolíticas que causam o amaciamento dos frutos. DONG et al. (2000) avaliaram a ação de lactato de cálcio na manutenção da firmeza em peras Bosc minimamente processadas e concluíram também haver efeito significativo do cálcio na textura das frutas mergulhadas em solução contendo $1 \%$ de lactato de cálcio, em comparação com aquelas mergulhadas apenas em água. O efeito do cálcio na firmeza foi maior na medida em que sua concentração foi aumentada.

A ação da cisteína sobre o retardamento do escurecimento enzimático foi observada nos tratamentos T2 e T3, contendo $1,0 \%$ e $1,5 \%$ de Lcisteína, respectivamente, não apresentando diferença significativa $(\mathrm{P}>0,05)$ entre si para os valores de $\Delta \mathrm{E}$, mas foram significativamente diferentes das peras submetidas ao controle (sem revestimento) (Figura 2). PEREZ GAGO et al. (2006) estudaram o efeito de antioxidantes e filmes à base de proteína de soro de leite na alteração de cor, em maçãs minimamente processadas, e concluíram que os tratamentos que apresentaram maior inibição do escurecimento enzimático foram 1,0\% de ácido ascórbico e 0,5\% de císteína, ambos incorporados nos filmes à base de proteína. Verificaram também que os pedaços de maçãs tratados com solução aquosa de $0,3 \%$ e $0,1 \%$ de cisteína desenvolveram coloração rósea, enquanto esse efeito não foi evidenciado quando níveis similares de cisteína foram incorporados aos filmes estudados.

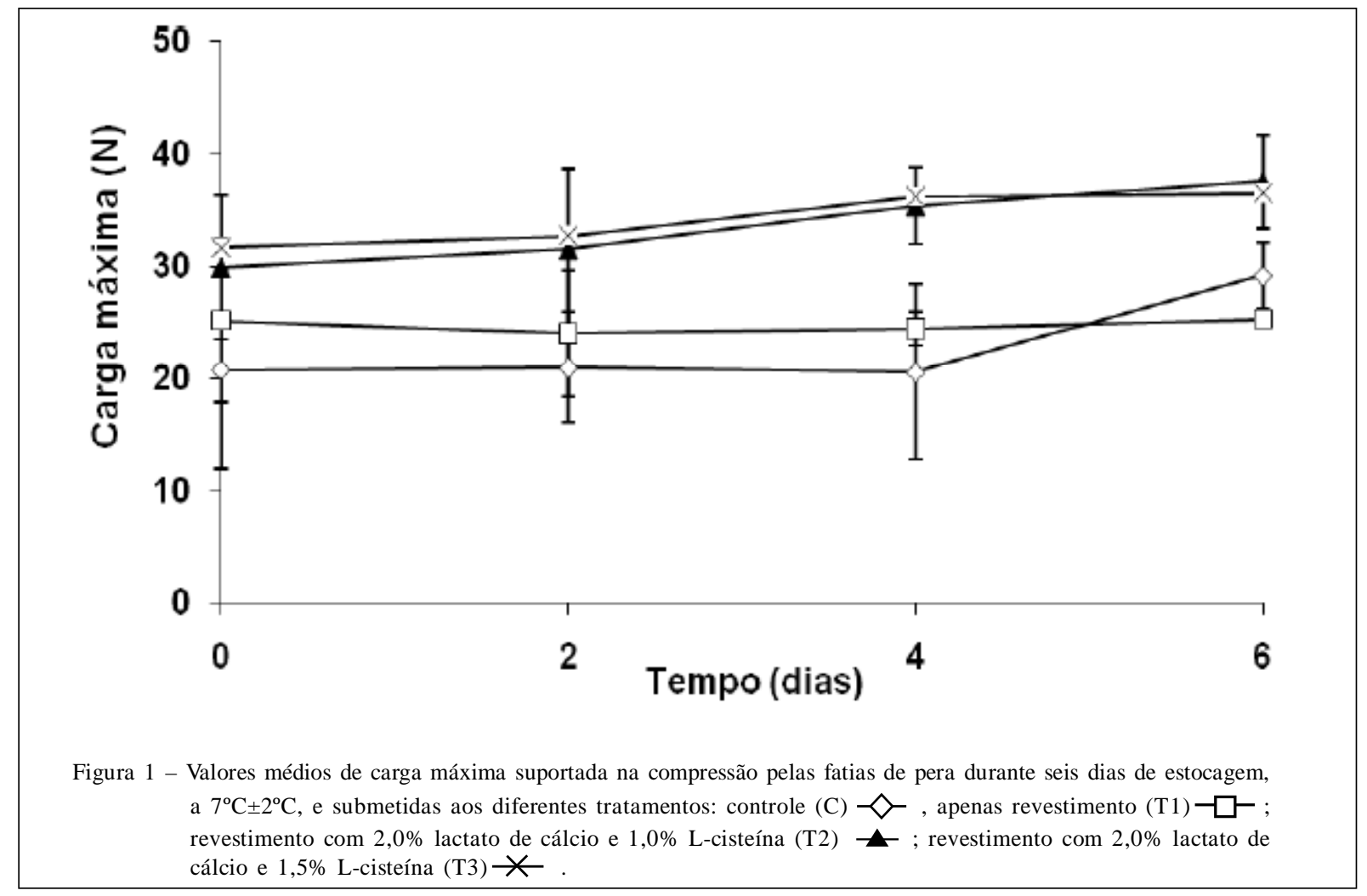

Ciência Rural, v.40, n.8, ago, 2010. 


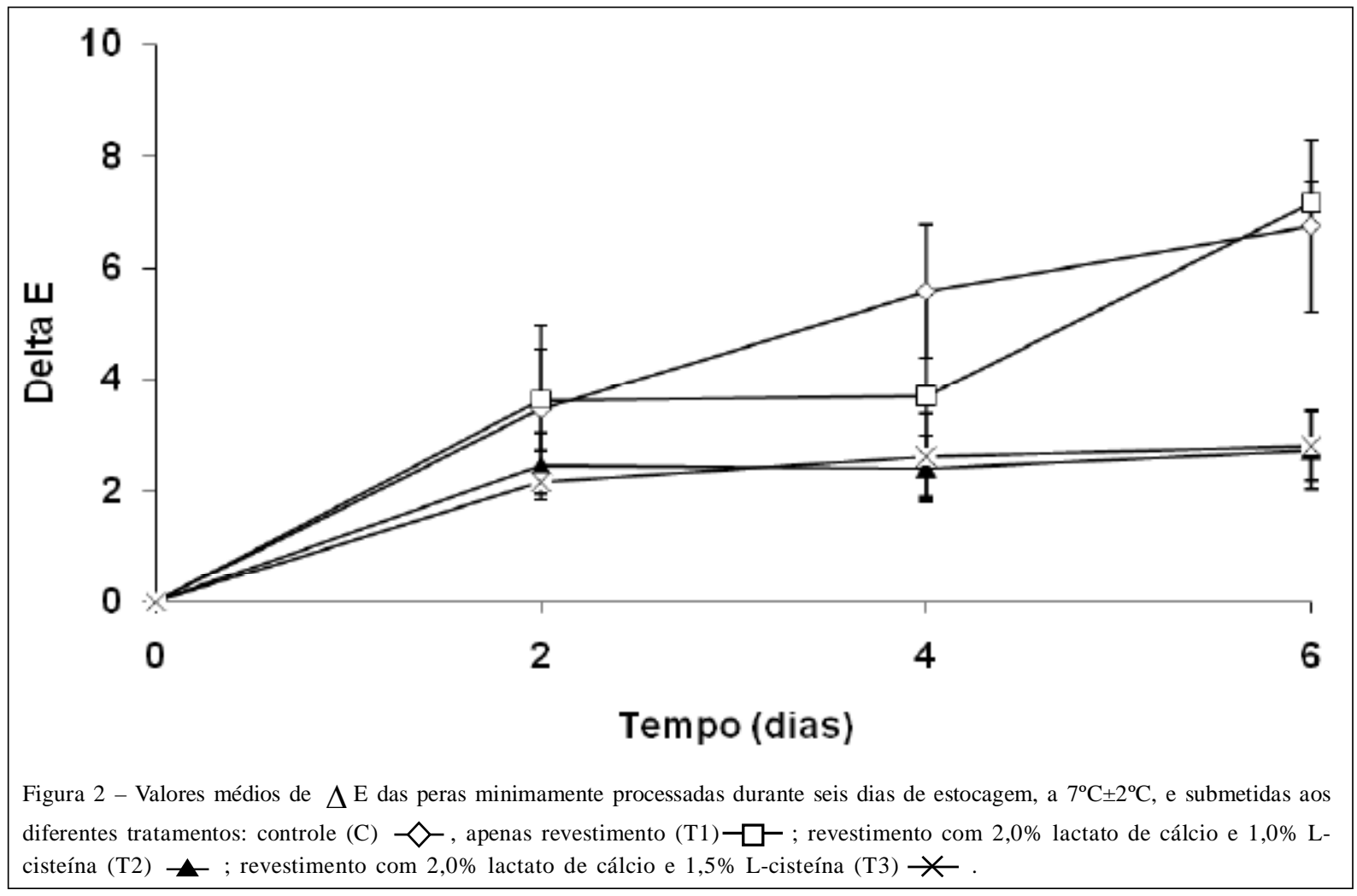

O aminoácido L-cisteína é um componente que pode ser adicionado a produtos minimamente processados para retardar o escurecimento enzimático. Esse composto age inibindo competitivamente a polifenoloxidase (PPO) ou realizando acoplamento oxidativo de o-quinonas, sendo regeneradas aos precursores o-difenóis e sendo evitada a formação de pigmentos marrons (RICHARD-FORGET et al., 1992). Porém, cuidados devem ser tomados para evitar seu uso em altas concentrações, pois podem causar odores residuais nos produtos alimentícios.

\section{Análises microbiológicas}

O crescimento de enterobactérias foi inibido pelo lactato de cálcio apresentando uma redução decimal de 3,16 e 3,05 para os tratamentos T2 e T3, respectivamente, em relação ao controle (C), ao final de seis dias de estocagem a $7^{\circ} \mathrm{C} \pm 2$ (Figura 3 ). Resultado semelhante foi observado para a contagem de psicrotrófilos, em que ocorreu uma redução decimal de 2,43 e 3,03 para os tratamentos T2 e T3, respectivamente, em relação ao controle $(\mathrm{C})$, no sexto dia de estocagem (Figura 4). Não houve diferença significativa $(\mathrm{P}>0,05)$ entre os tratamentos $\mathrm{T} 2$ e $\mathrm{T} 3$, mas estes apresentaram contagens significativamente menores em relação a $\mathrm{C}$ e $\mathrm{T} 1$, ao final de seis dias de estocagem a $7^{\circ} \mathrm{C} \pm 2^{\circ} \mathrm{C}$, em ambas as contagens.
BINGOLE BOSTAN (2006) avaliaram o efeito de três níveis de lactato de sódio $(0,6 \%, 1,2 \%$ e 1,8\%) sobre o crescimento de bactérias aeróbicas em linguiças e concluíram que o lactato retardou o crescimento, dependendo da concentração utilizada.

Os sais de ácido lático mostram efeito de conservação pelo decréscimo da atividade de água dos produtos onde são adicionados, exibindo efeito inibitório específico (SHELEF, 1994). Os sais de lactato podem ser alternativas para a substituição de compostos clorados com o objetivo de retardar o crescimento bacteriano e garantir a manutenção da segurança alimentar. A utilização de produtos à base de cloro em alimentos minimamente processados pode contribuir para a formação de gosto amargo, além do questionamento quanto ao seu uso por ser precursor na formação de cloraminas orgânicas (SREBERNICH, 2007).

\section{CONCLUSÃO}

O uso de revestimentos adicionados de Lcisteína e lactato de cálcio foi eficiente para prolongar a vida útil e manter a qualidade de pera minimamente processada durante seis dias a $7^{\circ} \mathrm{C} \pm 2^{\circ} \mathrm{C}$. O lactato de cálcio pode ser uma alternativa ao uso de cloreto de cálcio na manutenção de textura, além do lactato se 


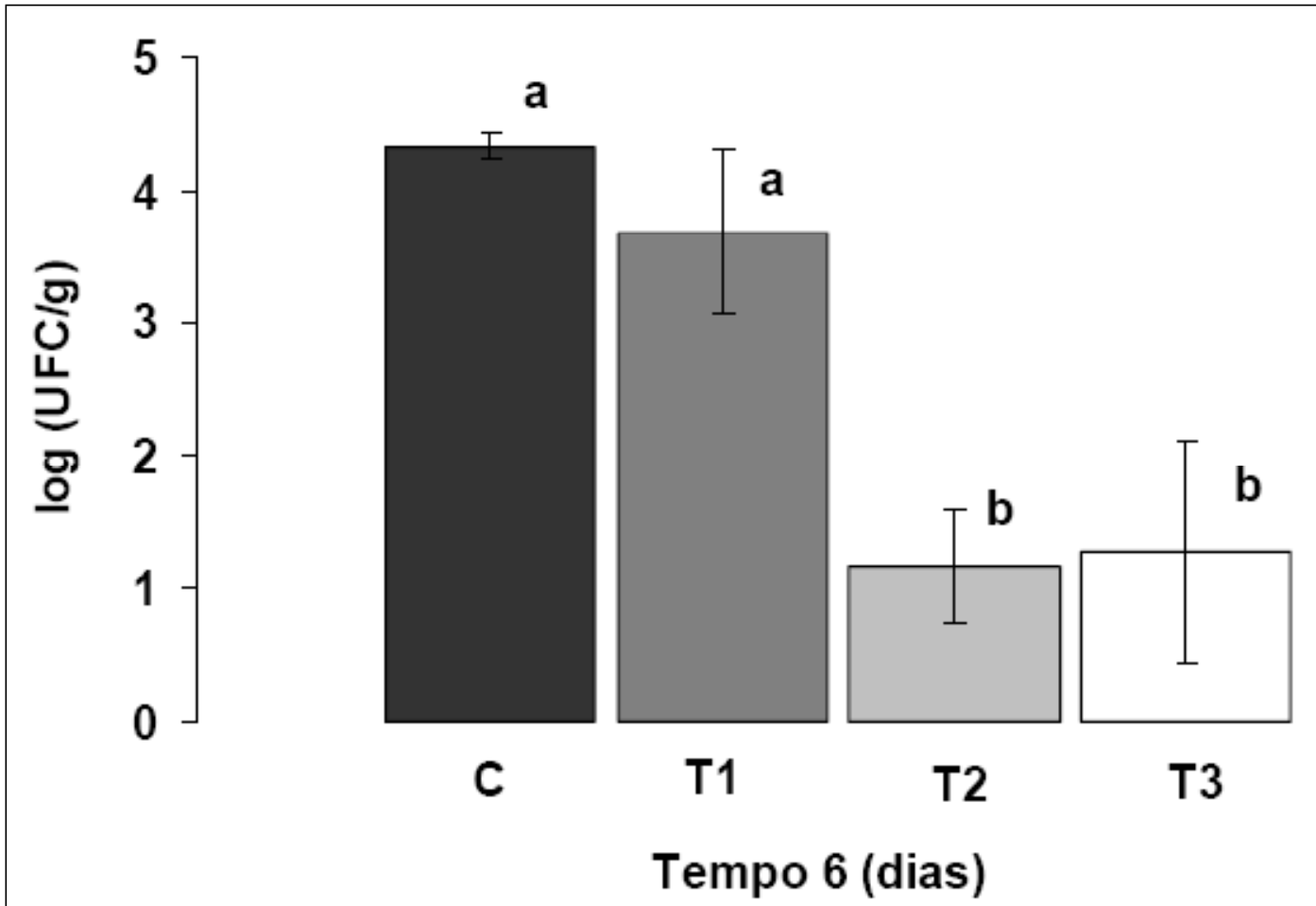

Figura 3 - Contagem de enterobactérias das peras minimamente processadas ao final de seis dias de estocagem, a $7^{\circ} \mathrm{C} \pm 2^{\circ} \mathrm{C}$, e submetidas aos diferentes tratamentos: controle (C), apenas revestimento (T1); revestimento com 2,0\% lactato de cálcio e 1,0\% L-cisteína (T2); revestimento com 2\% lactato de cálcio e 1,5\% L-cisteína (T3). Barras seguidas pela mesma letra não diferem entre si pelo teste de Tukey, com nível de $5 \%$ de significância.

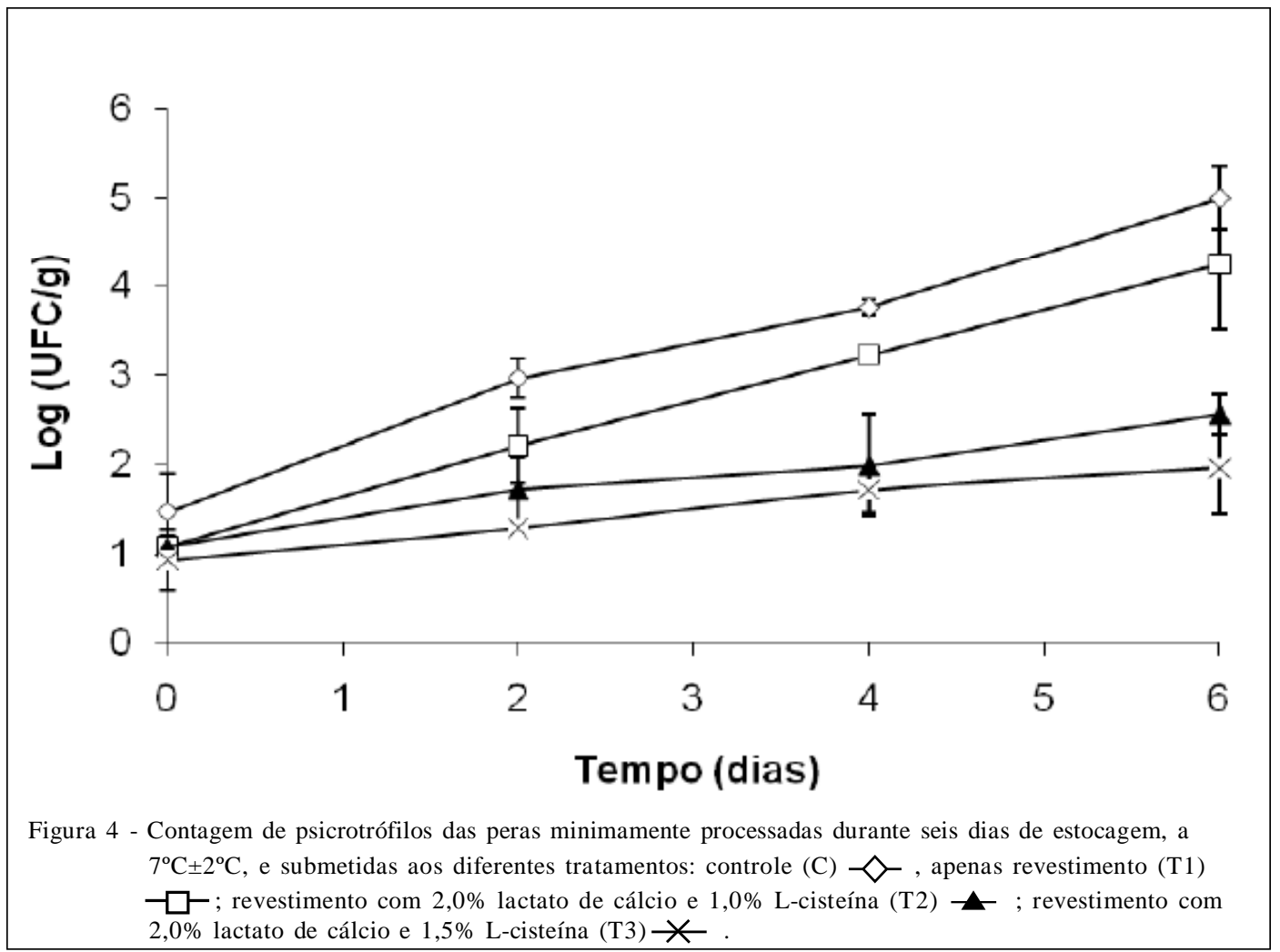

Ciência Rural, v.40, n.8, ago, 2010. 
apresentar como agente antimicrobiano. A L-cisteína foi eficiente na inibição do escurecimento enzimático.

\section{AGRADECIMENTOS}

\author{
CNPq, FAPEMIG, FINEP
}

\section{REFERÊNCIAS}

BINGOL, E.B.; BOSTAN, K. Effect of sodium lactate on the microbiological quality and shelf life of sausages. Turkish Journal of Veterinary and Animal Science, v. 31, n.5, p.333-339, 2007. Disponível em: < http:// journals.tubitak.gov.tr/veterinary/issues/vet-07-31-

5/vet-31-5-8-0608-20.pdf>. Acesso em: 3 fev. 2009.

BRASIL. Ministério da Saúde. Agência Nacional de Vigilância Sanitária. Métodos físico-químicos para análise de alimentos. Brasília: Ministério da Saúde, 2005. 1004p.

CHIEN, P-J. et al. Effect of edible chitosan coating on quality and shelf life of sliced mango fruit. Journal of Food Engineering, v.78, n.1, p.225-229, 2007. Disponível em: < http://dx.doi.org/10.1016/j.jfoodeng.2005.09.022>. Acesso em: 15 mar. 2008. doi: 10.1016/j.jfoodeng.2005.09.022.

DEBEAUFORT, F. et al. Edible films and coatings: tomorrow packaging: a review. Critical Reviews in Food Science and Nutrition, v.38, n.4, p.299-313, 1998. Disponível em: <http://dx.doi.org/10.1080/10408699891274219>. Acesso em: 15 mar. 2008. doi: 10.1080/10408699891274219.

DONG, X. et al. Extending shelf life of fresh-cut pears. Journal of Food Science, v.65, n.1, p.181-186, 2000. Disponível em: <http://dx.doi.org/10.1111/j.13652621.2000.tb15976.x>. Acesso em: 15 mar. 2008. doi: 10.1111/j.1365-2621.2000.tb15976.x.

GENNADIOS, A. et al. Mechanical and barrier properties of egg albumen films. Journal of Food Science, v.61, n.3, p.585-589, 1996. Disponível em: <http://dx.doi.org/10.1111/ j.1365-2621.1996.tb13164.x>. Acesso em: 3 fev. 2009. doi: 10.1111/j.1365-2621.1996.tb13164.x.

LUNA-GUZMÁN, I.; BARRETT, D.M. Comparison of calcium chloride and calcium lactate effectiveness in maintaining shelf stability and quality of fresh-cut cantaloupes. Postharvest Biology and Technology, v.19, p.61-72, 2000. Disponível em: < http:// dx.doi.org/10.1016/S0925-5214(00)00079-X>. Acesso em: 3 fev. 2009. doi: 10.1016/S0925$5214(00) 00079-x$

PAULA, N.R.F. et al. Qualidade de produtos minimamente processados e comercializados em gôndolas de supermercados nas cidades de Lavras-MG, Brasília-DF e São Paulo-SP. Ciência e Agrotecnologia, v.33, n.1, p.219-227, 2009. Disponível em: <http://dx.doi.org/10.1590/S141370542009000100031>. Acesso em: 10 nov. 2009. doi: 10.1590/S1413-70542009000100031.

PEREZ-GAGO, M.B. et al. Color changes of fresh-cut apples coated with why protein concentrate-based edible coatings. Postharvest Biology and Technology, v.39, n.1, p.84-92, 2006. Disponível em: <http://dx.doi.org/10.1016/ j.postharvbio.2005.08.002>. Acesso em: 10 nov. 2009. doi: 10.1016/j.postharvbio.2005.08.002.

PINHEIRO, A.C.M. et al. Influência do $\mathrm{CaCl}_{2}$ sobre a qualidade pós-colheita do abacaxi cv. pérola. Ciência e Tecnologia de Alimentos, v.25, n.1, p.32-36, 2005. Disponível em: <http://dx.doi.org/10.1590/S0101-20612005000100006>. Acesso em: 10 nov. 2009. doi: 10.1590/S010120612005000100006 .

RAYBAUDI-MASSILIA, R.M. et al. Edible alginate-based coating as carrier of antimicrobials to improve shelf-life and safety of fresh-cut melon. International Journal of Food Microbiology, v.121, n.3, p.313-327, 2008. Disponível em: <http://dx.doi.org/10.1016/j.ijfoodmicro.2007.11.010>. Acesso em: 10 nov. 2009. doi: 10.1016/ j.ijfoodmicro.2007.11.010.

REIS, C.M.F. et al. Qualidade e vida de prateleira de banana 'prata' minimamente processada. Ciência e agrotecnologia, v.28, n.3, p.696-702, 2004. Disponível em: < http://www.editora.ufla.br/site/_adm/upload/revista/283-2004_29.pdf>. Acesso em: 10 nov. 2009.

RICHARD-FORGET, F.C. et al. Cysteine as an inhibitor of enzymatic browning: 2. kinetic studies. Journal of Agricultural and Food Chemistry, v.40, n.11, p.21082113, 1992. Disponível em: <http://dx.doi.org/10.1021/ jf00023a014>. Acesso em: 10 nov. 2009. doi: dx.doi.org/ $10.1021 / \mathrm{jf00023a014.}$

ROJAS-GRAU, M.A. et al. Alginate and gellan-based edible coatings as carriers as antibrownings agents applied on freshcut Fuji apples. Food Hydrocolloids, v.21, n.1, p.118-127, 2007. Disponível em: <http://dx.doi.org/10.1016/ j.foodhyd.2006.03.001>. Acesso em: 3 fev. 2009. doi : 10.1016/j.foodhyd.2006.03.001.

SHELEF, L.A. Antimicrobial effects of lactates: a review. Journal of Food Protection, v.57, n.5, p.445-450, 1994. Disponível em: http://www.ingentaconnect.com/content/iafp/jfp/ 1994/00000057/00000005/art00016. Acesso em: 3 fev. 2009.

SILVA, P.S.L. et al. Distribuição do teor de sólidos solúveis totais em frutos de algumas espécies de clima temperado. Caatinga, v.15, p.19-23, 2002. Disponível em: <http://www.ufersa.edu.br/ caatinga/artigos/Caa1503.pdf>. Acesso em: 3 fev. 2009.

SREBERNICH, S.M. Utilização do dióxido de cloro e do ácido peracético como substitutos do hipoclorito de sódio na sanitização do cheiro-verde minimamente processado. Ciência e Tecnologia de Alimentos, v.27, p.744-750, 2007. Disponível em: <http://dx.doi.org/ 10.1590/S010120612007000400012>. Acesso em: 3 fev. 2009. doi: 10.1590/ S0101-20612007000400012.

VANDERZANT, C.; SPlitTSTOESSER, D.F. Compendium of methods for the microbiological examination of foods. 3.ed. Washington: American Public Health Association (APHA), 1992. 1219p.

$\mathrm{XU}$, S. et al. Determining optimum edible films for kiwi fruits using an analytical hierarchy process. Computers \& Operations Research, v.908, p.1-9, 2002. Disponível em: <http://dx.doi.org/10.1016/S0305-0548(02)00040-0>. Acesso em: 3 fev. 2009. doi: 10.1016/S0305-0548(02)00040-0. 